I conclude that the critic was so pained by my restricted use of the term " embryo" (as applied to plants) that he failed to read to the end of the chapter; otherwise he would not have stated that " experiments on plant physiology are not reached until chapters $\mathrm{I} 6$ and $\mathrm{I} 7$. " I agree that it is desirable to introduce plant physiology at an earlier stage in the course ; but, with the exception of germination (which is introduced in the Easter Term), the experiments seldom yield good results in the winter months. The school year begins towards the end of September, and the arrangement of the chapters (as stated in the preface) was based upon this assumption.

Oundle School, November Io.

I REGRET that Mr. Shann regards my review of his book as an "attack," and yet more that it calls from him the word " acerbity." The need for brevity compelled, perhaps, a certain bluntness; and I beg him to accept my assurance that it was solely to my regard for space in your columns that any such bluntness was due. It was from like considerations that I was obliged to refrain from indicating the authority for and adducing evidence in support of some of my criticisms.

With regard to the telson and biramous appendage I adhere to my statement. If Mr. Shann will refer to p. I44, $\$ 2 c$ of Marshall and Hurst (9th edition, I920), he will see that the telson is spoken of as a "region " of which a "segment" is a part. On referring to the passage in my copy of the " Cambridge Natural History " I find that when I first (presumably in I909) read its discussion of the relative claims of the biramous and foliaceous limb to be regarded as "primitive," I wrote in the margin "All the facts here stated, if taken in the reverse order, support the opposite theory." This is equally true to-day. If Mr. Shann will read H. M. Bernard's "The Apodidæ" (Macmillan, I892) I shall be astonished if he does not abandon the biramous as the "primitive" form of crustacean limb.

I duly noted that the course was arranged with the view of beginning in the Michaelmas Term; but as the very next sentence in the preface suggests modification of the order " at the discretion of the teacher," I felt justified in directing attention to the tardy appearance of plant physiology. The fact that some physiological experiments occur as early as chapter I4 does not seriously affect my criticism.

THE REviewer.

\section{The Mechanism of the Cochlea.}

IF I understand Dr. Perrett's letter in NATURE of November II, p. 633, his objection to Yoshii's experiments (which would apply equally to those of Wittmaack and Siebenmann) is based on the assumption that the intensity of the stimulation of every part of the cochlea must be proportional to the amplitude of the vibration set up in that part. I think this assumption is unwarranted, as the intensity of the sensory impression may vary also with the rapidity and the rate of change of direction of the movement imparted to the cilia of the hair-cells; i.e. as the total energy of the stimulus, not its amplitude only. Even supposing Dr. Perrett's assumption were correct, still Yoshii's deductions are not invalidated. Take the case in which he found that after prolonged subjection to high-pitched noise the basal portion of the cochlea showed degeneration. He deduces the logical conclusion that a high-pitched note stimulates the basal portion of the cochlea. It does not matter whether the stimulus thus applied were small as compared with that produced in the apical region by a prolonged low note or not. The apical region remained unaffected because it was not stimulated at all.

I cannot say that my model shows the shifting of the responses according to the intensity of the stimulus that Dr. Perrett says it should do, and possibly my knowledge of physics is insufficient to enable me to appreciate the reasons which lead him to look for this result. Personally, I have very little faith in the "crucial test" method of solving the problem of sound perception. The question has already been so long and so keenly debated, and so many " crucial tests " have been applied on both sides of the argument, that one almost begins to doubt the possibility of tone perception at all.

I have read Sir William Bayliss' letter (p. 632) with great interest. Naturally, it is very gratifying to me to find that my view of the mechanism of the cochlea has the support of so distinguished a physiologist. I am not very sanguine that my model will throw much light on the more refined details which he gives of the working of the cochlea. What the model actually shows is a definite, though not always well-defined, series of responses at different points along the " basilar membrane" for vibrations varying in frequency from about roo to about rooo D.V. per sec., the higher notes being at the proximal and the lower at the distal end of the scale. More than this I cannot claim for it. The mechanical difficulty of setting up a series of short threads, evenly spaced, evenly graduated in tension, and maintaining their spacing and tension unaltered during and after the processes of fixation, embedding and immersion in fluid, is so great that I have not succeeded so far in attaining anything approaching accuracy.

One need scarcely say that so imperfect an apparatus cannot, in its present state, throw much light on the more recondite points. If on the other hand we concentrate our attention on the more obvious, and more fundamental factors, I think the model does give some help. We recognise in the basilar membrane of the cochlea a threefold differentiation of its fibres, for length, tension and mass, and this differentiation is progressive, and in the same sense for each factor. We can embody those mechanical factors crudely in the form of a working model, and we get some sort of remote and inaccurate representation of what happens in the cochlea. The effects observed are undoubtedly resonance effects. It follows that the same resonance effects must take place in the cochlea. One cannot understand how Nature could evolve so elaborate a mechanism of resonance as we find in the cochlea, except by means of, and for the purpose of, increasingly accurate analysis of sound. G. WILKINSON.

$3^{8} 7$ Glossop Road, Sheffield, Nov. I5.

\section{An Offer of Nature Volumes.}

THE writer has been entrusted with the disposal of thirty-three volumes of NATURE (unbound, as issued) which their owner wishes to present to some library in the war-devastated area. These consist of vols. 50 to 56,74 to 92,97 and 98 , and I03 to 107 . A few parts are missing. Should any reader of NATURE know of some one who may be communicated with for this purpose, the information would be gratefully received. M. Gheury de Bray.

40 Westmount Road, Eltham, S.E.9, November I3. 